\title{
Los procesos de conocimiento como marco de la investigación en Documentación
}

\section{Francisco Javier García Marco}

El concepto de información sigue ocupando un lugar importante en las páginas de esta revista. En este número los ingenieros Beatriz Gil y Pedro Marijuán exploran sus relaciones con los conceptos de orden, desorden, entropía y negaentropía, creados entrono al paradigma de la información termodinámica, para aproximarse desde modelos más biológicos a posiciones comunes entre los documentalistas, que unen información y relevancia en un dúo indisoluble.

Sin embargo, el concepto de información sigue resultado confuso para el diálogo interdisciplinar, y, por tanto, para la construcción científica denuestra disciplina. Afortunadamente, el concepto de información relevante nos reconduce al de conocimiento. Los conocimientos son estructuras informacionales capaces de dirigir la energía humana o mecánica hacia la cración de nuevos estados de información en el medio y en el propio organismo. La información relevante es el alimento denuestro sistema cognitivo, el cual absorve y asimila sólo aquella información para la que tiene preguntas. Del mismo modo, en definitiva, como nuestro sistema visual procesa la luz.

Los sistemas de conocimientos han de evolucionar al mismo ritmo que el sistema real que representan. Si el medio no cambiara, no necesitaríamos nueva información. Precisamente la naturaleza ha seleccionado como más adaptativos aquellos sistemas nerviosos capaces de

Por todo ello, los conocimientos no son estáticos ni autosufientes. Antes al contrario, un conocimiento cerrado y estático es un conocimiento enfermo, que terminará produciendo desajustes al sistema que lo utiliza.

La naturaleza del conocimiento es esencialmente dinámica. Los conocimientos reclaman datos, información relevante. En cuento la información alcanza al 
sistema cognitivo interacciona con éste corroborándolo, poniéndolo en cuestión o, incluso, desmontándolo.

El conocimiento humano, además, es un sistema distribuido, compuesto de células autónomas — cada uno de nosotros- pero más dependientes de lo que muchas veces estamos dispuestos a admitir. Sin negar la autonomía, a veces genial, de los seres humanos, está claro que los grupos sociales crean sus propios sistemas de conocimiento, distribuidos entre todos sus miembros, y a los que intentan reconducir hacia los huecos necesarios. Pensemos en nuestro sistema educativo o de Ciencia y Tecnología.

El científico de la información social ha de intentar comprender en primer lugar el mundo del conocimiento social, para a partir de él, comprender qué es información relevante y qué información es relevante. Su centro son los procesos de conocimiento social —y su mediación individual—, procesos ligados necesariamente a actos comunicativos porque el acto de comunicación es esencial en un mundo social, que además soporta una red de conocimientos distribuida.

El mundo distribuido del conocimiento social es un mundo de cooperación y competencia, de supervivencia y muerte, de azar y de necesidad. Semeja más a un complejísimo ecosistema que a una enciclopedia alfabética o temática, la cual no puede ser más que el parcial almacen de algunos de los grupos dominantes de éxito, diríamos ahora- de la selva del conocimiento.

Desde este punto de vista, el conocimiento aparece como el eslabón perdido entre el estudio de la información como realidad objetiva y el acto de comunicación como proceso subjetivo y social. Las estructuras de conocimiento pueden representarse intersubjetivamente y se puede estudiar su relación con actos públicos y observables. Para ello, nuestros modelos de conocimiento social habrán de ser más biológicos y menos mecánicos, por más que lo mecánico va a tener un papel cada vez mayor en el mundo del conocimiento social.

Zaragoza, a 30 de diciembre de 1996.

Scire. 2 : 1 (en.-jun. 1996). 